\title{
Homo-epitaxial growth of single crystal diamond in the purified environment by active $O$ atoms
}

Jinlong Liu ${ }^{\mathrm{a}}$, Liangzhen Lin ${ }^{\mathrm{a}}$, Y un Zhao ${ }^{\mathrm{a}}$, Yuting Zheng ${ }^{\mathrm{a}}$, Kang An ${ }^{\mathrm{a}}$, Junjun Wei ${ }^{\mathrm{a}}$, Liangxian $\mathrm{Chen}^{\mathrm{a}}$, Lifu Hei ${ }^{\mathrm{a}}$, Jingjing Wang ${ }^{\mathrm{b}}$, Zhihong Feng ${ }^{\mathrm{b}}$, Chengming $\mathrm{Li}^{\mathrm{a} *}$

${ }^{a}$ Institute for Advanced Materials and Technology, University of Science and Technology Beijing, Beijing 100083, P.R. China

${ }^{\mathrm{b}}$ Science and Technology on ASIC Laboratory, Hebei Semiconductor Research Institute, Shi Jia Zhuang 050051, PR China

\begin{abstract}
:
The pure oxygen was introduced into the growth environment of the single crystal diamond with different contents, and the growth characteristics of single crystal diamond and the reaction dynamics in the plasma were studied in detail. As the ratio of $\mathrm{O}_{2}$ to $\mathrm{H}_{2}$ is up to $1.5 \%$, the unique shaped etching pits with eight symmetric crystallographic planes appear. Optical emission spectra present typical characteristic radicals in the $\mathrm{O}_{2}$ incorporated growth environment. W ith amount of $\mathrm{O}_{2}$ increases, the growth rate decreases gradually due to the low active carbon source concentration and electron temperature. In the carbon contained hydrogen plasma, $\mathrm{O}_{2}$ will react with $\mathrm{CH}$ radicals preferentially at low concentration and the dynamic equilibrium of $\mathrm{CH}$ and $\mathrm{C}_{2}$ radicals was achieved at the $\mathrm{O}_{2}$ concentration of $0.5 \%$ and $1 \%$. Accompanying with the $\mathrm{O}_{2}$ addition, the nitrogen and silicon related impurities have been reduced during the epitaxial growth process. Meanwhile, all of the FWHM of characteristic peaks in Raman decrease obviously after the epitaxial growth without and with $\mathrm{O}_{2}$ addition, and FWHM of most samples are about $2.6 \mathrm{~cm}^{-1}$, which are comparable with the natural type IIa SCD without stress.
\end{abstract}

Key word:Diamond; Single crystal growth; OES; Purification; Epitaxial growth.

First a uthor: Jinlong Liu, E-Mail: liujinlong@, ustb.edu.cn

*Corresponding a uthor: Chengming Li, E-Mail: chengmli@,mater.ustb.edu.cn

No.30 Xueyuan Road Haidian Distric, Beijing 100083

\section{Introduction}

Diamond has been widely researched due to its excellent mechanical, optical, thermal and electrical properties such as the highest hardness, highest thermal conductivity, almost allband transmission, the highest carrier mobility and so on[1-3]. Based on the the properties, high quality diamond has been widely applied in the cutting tools[4], heat sinks[5], highpower windows[6] and electronic devices[7-8], especially the jewelries[9].

In recent years, the single crystal diamond (SCD) preparation technique based on chemical vapor deposition (CVD) has achieved dramatical progress. First of all, the size of single crystal diamond was enlarged by homo-epitaxial and hetero-epitaxial growth. One promising technology to obtain large size wafer is the mosaic fabrication method based on homo epitaxy[10-11]. The maximum size present is $4 \times 6 \mathrm{~cm}^{2}$, reported by AIST[11]. However, there is an obvious boundary between the mosaic plates of SCD. Meanwhile, researchers also seek out the hetero-epitaxial growth based on the metal oxide and Ir. Until now larger than $10 \mathrm{~mm} \times 10 \mathrm{~mm} \mathrm{SCD}$ has been obtained by using $\mathrm{SrTiO}_{3}[12]$ or YSZ [13] as the buffer layer to reduce the interface stress. A drawback of hetero-epitaxial growth is the high dislocation density. Secondly, the dislocation density of the epitaxial diamond has been improved by using a low dislocation density crystal as the seed. After growth, the dislocation density of the epitaxial layer was $400 \mathrm{~cm}^{-2}$ [14]. Thirdly, the high growth rate was achieved by adjusting the growth parameters and adding a small amount of $\mathrm{N}_{2}$. The growth rate of up to $165 \mathrm{um} / \mathrm{h}$ was obtained for the single crystal diamond up to $18 \mathrm{~mm}$ in thickness at high power density[15].

Until now, to achieve high pure single crystal diamond deposition with limited impurities is another topic. Generally the background concentration of nitrogen and silicon is hard to be 
limited. High pure single crystal diamond layers have always been obtained on the high quality single crystal diamond seed under the harsh growth conditions, which leads to a high production cost. Moreover, as one of the best choices for electronics and quantum computing, requirement of high pure diamond crystal is an even greater obstacle, which requires the background concentration of nitrogen and silicon to reach less than one part per billion[16]. It is an effective method to improve the crystalline quality of single crystal diamond by adding special reaction groups in the CVD environment. The high growth rate of single crystal diamond was obtained without any loss of crystalline quality by incorporating argon(Ar) due to the higher gas temperature of the plasma and activated $\mathrm{H}$ atoms[17]. N-related gas addition such as $\mathrm{N}_{2} \mathrm{O}$ could generate a much smooth growing surface and improve the crystallographic quality and orientation of SCDs due to the step flow mode[18]. O-related gas addition including $\mathrm{O}_{2}, \mathrm{CO}$ and $\mathrm{CO}_{2}$ could be used to improve the quality of diamond by the preferential etching of the non-diamond carbon by activated $\mathrm{O}$ atoms[19]. Besides this, it can also hinder the diamond cracks to promote the growth of thicker single crystal diamond layer[20]. Although it has been found that the O-related gas addition could improve the quality obviously, the growth mechanism related with the reaction dynamics in the plasma is not systematic. The single crystal diamond growth with O-related gas addition is a very competitive method to control the impurity for application in the electronic-grade or quantum-grade diamond. The research on the growth characteristics of the single crystal diamond with O-related gas addition is necessary.

In this paper, the pure oxygen was introduced into the growth environment of the single crystal diamond with different contents. The reaction dynamics in the plasma was analyzed. Correspondingly, the crystal quality of single crystal diamond with different $\mathrm{O}_{2}$ addition was characterized. This research will provide the fundamental results for the high pure diamond growth and possibility of application in the diamond electronics and quantum calculation.

\section{Experime ntal}

\subsection{Epitaxial growth of the single crystal diamond}

The single crystal diamond growth experiments were conducted in a $2.45 \mathrm{GHz}$ microwave chemical vapor deposition (CVD) system with a typical quartz-bell structure. Before the growth, the commercial tool-grade high pressure high temperature (HPHT) seeds with roughness of less than $5 \mathrm{~nm}$ were boiled in the solution of $\mathrm{H}_{2} \mathrm{SO}_{4}$ mixed $\mathrm{HNO}_{3}$ with volume ratio of 5:1 for $30 \mathrm{~min}$ to remove the residue inclusions and contaminations on the surface. The HPHT diamond seeds shows typical peak at about $59.8^{\circ}$ in the rocking curve of X-ray diffraction (XRD), indicating the (004) plane orientation. Then the seeds were placed in a molybdenum holder. After the chamber pressure was below $0.1 \mathrm{~Pa}$, hydrogen with purification of higher than $99.999 \%$ was filled in. The plasma was ignited after the chamber pressure reached $1 \mathrm{kPa}$ and the seed temperature was adjusted by increasing the MW power and chamber pressure correspondingly. After the carbon source and different content $\mathrm{O}_{2}$ were added to grow diamond epitaxially without intentional plasma etching, the growth temperature was kept at $900^{\circ} \mathrm{C}$. The detailed growth parameters were shown in Table 1. During the growth stage, the optical emission spectroscopy (OES) was used to test the reaction groups in the plasma, as shown in Fig.1. The optical fiber probe was fixed at $10 \mathrm{~cm}$ from the center of plasma. The optical spectrum ranges from $300 \mathrm{~nm}$ to $700 \mathrm{~nm}$, which covers all the characteristic peak of activated groups. The relative intensity changes of the peaks corresponding to the different radicals were used to show the reaction dynamics in the $\mathrm{O}_{2}$ incorporated environment.

\subsection{Epitaxial growth of the single crystal diamond}

After the epitaxial layer growth, the surface morphology was observed by optical microscope and atomic force microscope(AFM). The impurity content in the grown diamond layers was detected by photoluminescence (PL) spectrum with laser wavelength of $532 \mathrm{~nm}$. The crystal quality of the diamond seeds and the epitaxial layers was characterized systematically 
by Raman spectroscopy with laser wavelength of $514 \mathrm{~nm}$. To exclude the effect of diamond seed on the Raman characteristics, the declined percentage of the full width at half maximum (FWHM) of feature peak after epitaxial growth was calculated based on the Equation (1) and analyzed, where $F W H M_{\mathrm{S}}$ and $F W H M_{\mathrm{E}}$ are the $F W H M$ of the feature peak of the diamond seed and epitaxial layer, respectively.

$$
\text { Declined percentage }=\frac{F W H M_{\mathrm{S}}-F W H M_{\mathrm{E}}}{F W H M_{\mathrm{S}}}
$$

Equation (1)

\section{Results and Discussion}

The surface morphology of epitaxial single crystal diamond layers with different concentrations of $\mathrm{O}_{2}$ addition are shown in Fig. 2. It shows smooth surface composing of the rounded hillocks in Fig.2(A1), which may be due to the low supersaturation of active carbon related radicals. At the edge of the sample, it presents the pyramid growth mode resulting from the defects of the diamond seeds. As the $\mathrm{O}_{2}$ concentration increases, the epitaxial layer surface shows similar hillock morphology and the pyramids at the edge disappear because the $\mathrm{O}$ related species remove the defects induced "unepitaxial crystallites"[21]. When the $\mathrm{O}_{2}$ concentration is up to $1.5 \%$, besides the hillock morphology, the black dots in the center appear coming from the plasma etching. It means in the diamond growth environment, the etching effect instead of growth becomes dominate in the center. As the $\mathrm{O}_{2}$ content increases, the etching dots become more and more. It is easy to understand that the $\mathrm{O}$ related groups such as $\mathrm{OH}$ have higher etching efficiency. We further investigated the etching dots on the surface of the grown epitaxial layer with $\mathrm{O}_{2}$ concentration of $2.5 \%$ in Fig.2(A6), as shown in Fig.3. The black dots in different size show the similar shaped pits with eight symmetric crystallographic planes, which is obviously different from the ones in the $\mathrm{H}_{2} / \mathrm{O}_{2}$ etching plasma and $\mathrm{CH}_{4} / \mathrm{H}_{2}$ growth environment[22]. In the Fig.3(b), it shows the typical etching pit. The 3D morphology shows the crystallographic faces clearly combined with the smaller pits. Until now there have been few reports on this kind of etching dots. In order to confirm the crystallographic faceting, the surface profile cross the center of one crystallographic plane was tested by AFM and the results are shown in Fig.4. The angle between the plane of the etching pits and the sample surface was obtained by calculating the slope of the surface profile, and angle of about is $13.9^{\circ}$. Furthermore, we calculated the angle between the assumed plane of $\left(h_{1} k_{1} l_{1}\right)$ and the surface plane of the epitaxial layer (004) using the equation for cubic system. It could be deduced that the crystal indices of the etching pits satisfy the relationship of $16.2\left(h_{1}^{2}+k_{1}^{2}\right)=l_{1}^{2}$. Based on this relationship, $\{129\}$ crystal planes for the etching pits may be predicted. It indicates this crystal planes will be etched preferentially in the current composition of $\mathrm{CH}_{4} / \mathrm{H}_{2} / \mathrm{O}_{2}$ plasma environment. The relationship between the apexes of the pits and the defects cannot be confirmed. However, these geometry is induced by the plasma containing $\mathrm{O}$ composition, depending on the ratio of etching rate between the vertical direction and the face direction [23]. Meanwhile, the Raman mapping of sample A6 based on the intensity of characteristic peak of diamond was measured and shown in Fig.5. Two distinguished kinds of characteristic peak intensity can be found from the etching pits and the normal surface. It is noteworthy that in all the etching pits areas, there is one plane showing the similar intensity with the surface. The reasonable explanation for this phenomenon is under investigation.

OES is a sensitive technique to in-situ monitor the species in the plasma during the CVD SCDs growth[24]. The optical emission spectra while growing SCD with addition of $\mathrm{O}_{2}$ in different concentrations were recorded and shown in Fig.6. The characteristic radicals of $\mathrm{C}_{2}(470,516.5$ and $563.1 \mathrm{~nm}), \mathrm{CH}(431.5 \mathrm{~nm}), \mathrm{H}_{\alpha}(656 \mathrm{~nm}), \mathrm{H}_{\gamma}(434.1 \mathrm{~nm})$, and $\mathrm{H}_{\beta}(468.1 \mathrm{~nm})$ are all presented and the intensities vary with increase of $\mathrm{O}_{2}$ concentration. The $\mathrm{OH}$ radicals responsible for the etching effect cannot be seen due to relative low $\mathrm{O}_{2}$ addition concentration. The high intensity $\mathrm{C}_{2}$ peak shows a typical feature under the plasma conditions of high pressure, $\mathrm{CH}_{4} / \mathrm{H}_{2}(5 \%)$ ratio and power density. It can be observed that intensities of $\mathrm{C}_{2}, \mathrm{CH}, \mathrm{H}_{\alpha}$ radicals decrease in Fig.7. Meanwhile, the band at 400-405nm gradually disappears with $\mathrm{O}_{2}$ 
addition and emissions at $390 \mathrm{~nm}$ become stronger, indicating the amount increase of $\mathrm{CO}$ present in the plasma[25]. The decrease rate of $\mathrm{C}_{2}$ radicals is much larger than that of $\mathrm{CH}$ and radicals. As the $\mathrm{O}_{2}$ concentration increases, the active $\mathrm{O}$ atoms will react with the carbon containing species and the $\mathrm{H}$ atoms. Correspondingly, the $\mathrm{CO}$ and $\mathrm{OH}$ species generate. Although no obvious $\mathrm{OH}$ groups were found in the OES due to the small concentration, it can be speculated that $\mathrm{OH}$ groups were generated because of its strong etching effect. Then increase of the $\mathrm{O}$ atoms reduce the contents of the $\mathrm{C}_{2}, \mathrm{CH}$ and $\mathrm{H}_{\alpha}$ in the plasma. Based on the change of the reaction groups, the existed chemical reactions in the plasma are speculated below.

\section{$\mathrm{CH}_{4} \rightarrow \mathrm{C}_{2} \mathrm{H}_{6}+\mathrm{H}, \mathrm{CH}_{4} / \mathrm{C}_{2} \mathrm{H}_{2} \rightarrow \mathrm{CH}+\mathrm{H}, \mathrm{C}_{2} \mathrm{H}_{2} / \mathrm{CH}+\mathrm{O}_{2} \rightarrow \mathrm{CO}+\mathrm{OH}, \mathrm{H}_{2} / \mathrm{H}+\mathrm{O}_{2} \rightarrow \mathrm{OH}+\mathrm{O}$}

The dependence of growth rate on the varying $\mathrm{O}_{2}$ concentration is shown in Fig.8. It decreases from 5.05 to 2.86 with increasing oxygen from $0 \%$ to $2.5 \%\left(\mathrm{O}_{2} / \mathrm{H}_{2}\right)$ in the plasma, which means $\mathrm{O}_{2}$ incorporation reduces the deposition rate of the single crystal diamond. The dependence of the ratio of $\mathrm{CH}$ to $H_{\alpha}$ emission intensity, $I(\mathrm{CH}) / I\left(H_{\alpha}\right)$, and $\mathrm{H}_{\gamma}$ to $\mathrm{H}_{\beta}$ emission intensity $\left(I\left(\mathrm{H}_{\gamma}\right) / I\left(\mathrm{H}_{\beta}\right)\right.$,) on the $\mathrm{O}_{2}$ addition is shown in Fig.8(a) and Fig.8(b). Both of them show the similar trends with the growth rate. In fact, the growth rate of the single crystal diamond is associated with the carbon source concentration and the electron temperature in the diamond growth environment. Generally, the $\mathrm{CH}$ radicals related to $\mathrm{CH}_{\mathrm{x}}$ species in the plasma are the precursor of diamond growth, and radicals have the function of the etching of nondiamond phase. More $\mathrm{CH}$ radicals can promote the epitaxial growth of diamond and more radicals will slower the growth of diamond relatively, even though radicals are beneficial to high-quality growth of diamond. As the $\mathrm{O}_{2}$ concentration increases, the carbon source concentration decreases, which will affect the growth rates. Meanwhile, is generally used to characterize the electron temperature in the plasma[26]. Without $\mathrm{O}_{2}$ addition, high electron temperature has long mean free path for the electron. The electrons collide with $\mathrm{H}_{2}$ molecules, promote the ionization of gas, accelerate the activation reaction, and ultimately enhance the growth rate. As $\mathrm{O}_{2}$ was added, the electron temperature decreases, the ionization degree of gas lowers, and the reaction process suppresses. It leads to the decrease of growth rate with $\mathrm{O}_{2}$ concentration increase. Though all samples were deposited at $900^{\circ} \mathrm{C}, \mathrm{O}_{2}$ incorporation changes the electron temperature and the intensity of all radicals in plasma, which induces the difference of growth rate.

$\mathrm{C}_{2}$ radical is the product of carbon-containing radicals under high power density. In Fig.9, dependence of and on $\mathrm{O}_{2}$ concentration is shown and it is found that rises firstly and then falls with increasing $\mathrm{O}_{2}$ concentration. It is because that $\mathrm{O}_{2}$ will react with $\mathrm{CH}$ radicals preferentially under low concentration of $\mathrm{O}_{2}$ [25]. With increasing $\mathrm{O}_{2}$ concentration, the consumption of $\mathrm{CH}$ radicals reaches saturation. $\mathrm{O}_{2}$ will combine more with $\mathrm{C}_{2}$ radicals and lead to the reaction rate increase. Therefore, we can find that decreases obviously at $\mathrm{O}_{2}$ concentration of $1.5 \%$. The changes slightly between $0.5 \% \mathrm{O}_{2}$ and $1 \% \mathrm{O}_{2}$, which indicates dynamic equilibrium of $\mathrm{CH}$ and $\mathrm{C}_{2}$ radicals reaches. During the epitaxial growth process, the relative intensity of radicals plays a significant role to grow high quality single diamond. $\mathrm{C}_{2}$ radical is also an important part for diamond growth, but high intensity of $\mathrm{C}_{2}$ radicals will increase the non-diamond component. Although the intensity of radicals decrease with the increasing $\mathrm{O}_{2}$ concentration, the also decreases as shown in Fig.9. The decrease of indicates that the crystal quality of single diamond could be improved with high $\mathrm{O}_{2}$ concentration addition.

The PL spectra were used to show the impurities in the epitaxial diamond layer in Fig.10. Without $\mathrm{O}_{2}$ addition, the diamond epitaxial layer shows obvious fluorescence characteristics. Two sharp peaks at $575 \mathrm{~nm}$ and $637 \mathrm{~nm}$ respectively, shows a large amount of $[\mathrm{N}-\mathrm{V}]^{0}$ and $[\mathrm{N}-$ $\mathrm{V}]^{-}$impurities existing in the layer. As the $\mathrm{O}_{2}$ concentration increases, no obvious impurity peaks could be found, which mean the epitaxial layer was purified by $\mathrm{O}_{2}$ incorporation. It is noteworthy that the diamond feature peak shows the highest intensity at $\mathrm{O}_{2}$ concentration of $1.5 \%$, which indicates the highest crystal quality. Due to $\mathrm{O}_{2}$ addition in plasma, it suppresses 
the formation of nitrogen vacancy and reduced the introduction of impurities during the epitaxial growth process. There are some reports on the quality improvement of the diamond by the oxygen plasma treatment [27] or oxygen addition into the hydrogen-methane plasma [20]. It was shown that oxygen addition can not only remove the nitrogen, silicon and hydrogen related impurities, but also hinder the diamond cracks to promote the growth of thicker single crystal diamond layer. Although no clear evidence was found, it can be speculated that the $\mathrm{OH}$ and $\mathrm{O}$ radicals in the plasma will react with these impurity and form such nonreactive species, such as $\mathrm{NO} / \mathrm{NO}_{2}, \mathrm{SiO} / \mathrm{SiOH}, \mathrm{H}_{2} \mathrm{O}$ and so on.

Raman spectroscopy was used to characterize the crystal quality of epitaxial growth layers with different concentrations of $\mathrm{O}_{2}$ incorporation, as shown in Fig.11. Fig.11(a) shows the first order Raman peaks of the diamond seeds and the grown layer under different concentrations of $\mathrm{O}_{2}$. In the atmosphere of no $\mathrm{O}_{2}$ addition and small amount $\mathrm{O}_{2}$ addition until $1.0 \%$, the Raman feature peak positions shift to higher wave number, which means there exists the compressive stress in the epitaxial layer. As the $\mathrm{O}_{2}$ concentration increases, the Raman shift difference between the diamond seed and the epitaxial layer becomes small, which may be attributed to the reduced thickness and the increased etching pits density. Meanwhile, the FWHM of feature peaks of the samples are shown in Fig.11(b). All of the FWHM decreases dramatically after the epitaxial growth. FWHM is a typical index to characterize the crystallinity. The impurities and the defects incorporated in the crystal lattice distortion will make the Raman peaks broaden. In our situation, all the crystal quality of the epitaxial layers grown with varying $\mathrm{O}_{2}$ concentration are improved though there are still many impurities in the epitaxial layer for the epitaxial layer without $\mathrm{O}_{2}$ growth. Except the A2 sample with FWHM of $3.68 \mathrm{~cm}^{-1}$, the FWHM of all samples are about $2.6 \mathrm{~cm}^{-1}$, which are comparable with the natural type IIa SCD without stress[28].

In addition, the FWHM of the epitaxial layer is strongly dependent on the diamond seed quality. In order to distinguish the effect of $\mathrm{O}_{2}$ addition from the changed FWHM, the declined percentage of the FWHM after epitaxial growth compared with the original diamond seed, is shown in Fig.12. The declined percentage of the Raman FWHM shows accelerated decrease trend as the concentration of $\mathrm{O}_{2}$ addition increases. Until $1.5 \% \mathrm{O}_{2}$ was added, the declined percentage levels off. Although the FWHM of the characteristic Raman peaks show decrease in different levels after epitaxial growth, the declined percentage decrease and go to a stable value excluding the diamond seed effect. Generally it is speculated that the added oxygen in the source gas, will generate strong etching on the defective part on diamond seed surface during diamond growth process and the reduced nitrogen, silicon and hydrogen related impurities will be beneficial to improve the crystal quality of the epitaxial layers. In our situation, the reverse phenomenon was observed. Meanwhile, it was reported that the FWHM could be decreased obviously when the $\mathrm{O}_{2}$ concentration was up to certain extent [29]. It should be associated with the concentration ratio among the carbon source, $\mathrm{H}_{2}$ and $\mathrm{O}_{2}$. Under higher $\mathrm{CH} / \mathrm{H}_{\alpha}, \mathrm{O}_{2}$ will mainly play a role to purify the growth environment in a low concentration and the best crystallinity could be obtained using the certain extent $\mathrm{O}_{2}$ as both improver for the growth environment and repairman on the diamond surface. For our situation, the $\mathrm{CH} / \mathrm{H}_{\alpha}$ is not so high; therefore, $\mathrm{O}_{2}$ will act as the improver and repairman in the low concentration. $\mathrm{O}_{2}$ further increase will lead to the obvious etching on the growth surface in some defective sites, in which situation, the repair effect will be adverse and the crystallinity could not be improved further.

\section{Conclusions}

The single crystal diamond epitaxial growth with $\mathrm{O}_{2}$ addition in the $\mathrm{H}_{2} / \mathrm{CH}_{4}$ plasma was studied in details. As the ratio of $\mathrm{O}_{2}$ to $\mathrm{H}_{2}$ is up to $1.5 \%$, the unique shaped etching pits with eight symmetric crystallographic planes appear. Optical emission spectra present typical characteristic radicals of $\mathrm{C}_{2}, \mathrm{CH}, \mathrm{H}_{\alpha}, \mathrm{H}_{\gamma}, \mathrm{H}_{\beta}$ and $\mathrm{CO}$ in the $\mathrm{O}_{2}$ added growth environment. With 
$\mathrm{O}_{2}$ increase, the growth rate shows gradual decrease trend due to the low active carbon source concentration and the electron temperature. In the carbon contained hydrogen plasma, $\mathrm{O}_{2}$ will react with $\mathrm{CH}$ radicals preferentially under low concentration of $\mathrm{O}_{2}$ and the dynamic equilibrium of $\mathrm{CH}$ and $\mathrm{C}_{2}$ radicals was achieved at the $\mathrm{O}_{2}$ concentration of $0.5 \%$ and $1 \%$. Accompanying with the $\mathrm{O}_{2}$ addition, it suppresses the formation of nitrogen vacancy and reduces the introduction of impurities during the epitaxial growth process. Meanwhile, all of the FWHM decrease obviously after the epitaxial growth without and with $\mathrm{O}_{2}$ addition and FWHM of most samples are about $2.6 \mathrm{~cm}^{-1}$, which are comparable with the natural type IIa SCD without stress.

\section{Acknowledge ments}

This work was sponsored by the National Natural Science Foundation of China (No. 51402013) and the National Key Research and Development Program of China (No. 2016YFE0133200) and European Union's Horizon 2020 Research and Innovation Staff Exchange (RISE) Scheme (No.734578). The authors deeply appreciate their financial support.

\section{References}

[1]Q.Liang, Y.F. Meng, C.S. Yan, S. Krasnicki, J. Lai, K. Hemawan, H. Shu, D. Popov, T. $\mathrm{Yu}$, W. Yang, H.K. Mao, R.J. Hemley,Developments in synthesis, characterization, and application of large, high-quality CVD single crystal diamond,J. Superhard Mater. 35(2013) 195-213.

[2] S. Terentyev, V. Blank, S. Polyakov, S. Zholudev, A. Snigirev, M. Polikarpov, T. Kolodziej, J. Qian, H. Zhou, Y. Shvyd'ko, Appl. Phys. Lett. 107 (2015) 111108.

[3] S. Shikata, Single crystal diamond wafers for high power electronics, Diam. Relat. Mat. 65 (2016) 168-175.

[4] S. Goel, X. Luo, R.L. Reuben, Wear mechanism of diamond tools against single crystal silicon in single point diamond turning process, Tribol. Int. 57(2013) 272-281.

[5] Y. Han, B.L. Lau, X. Zhang, Y.C. Leong, K.F. Choo, Thermal Management of Hotspots With a Microjet-Based Hybrid Heat Sink for GaN-on-Si Devices, IEEE T. Comp. Pack. Man.4 (2014) 1441-1450.

[6] G. Gantenbein, A. Samartsev, G. Aiello, G. Dammertz, J. Jelonnek, M. Losert, A. Schlaich, T.A. Scherer, D. Strauss, M. Thumm, D. Wagner, First operation of a stepfrequency tunable 1-MW gyrotron with a diamond brewster angle output window,IEEE T. Electron. Dev. 61(2014) 1806-1811.

[7] A. Marechal, N. Rouger, J.C. Crebier, J. Pernot, S. Korzumi, T. Teraji, E. Gheeraet, Model implementation towards the prediction of $\mathrm{J}(\mathrm{V})$ characteristics in diamond bipolar device simulations, Diam. Relat. Mat. 43 (2014) 34-42.

[8] Y.L. Li, Z.L. Wang, Q. Wang, X.X. Xia, J.J. Li, C.Z. Gu, Local electrical properties of hydrogenated (001) and (111) surfaces of single crystalline diamond, Vacuum, 83(2009) 1118-1122.

[9]R.J. Nemanich, J.A. Carlisle, A. Hirata, K. Haenen, MRS Bull. 39(2014) 490-494.

[10] H. Yamada, A. Chayahara, H. Umezawa, N. Tsubouchi, Y. Mokuno, S. Shikata, Fabrication and fundamental characterizations of tiled-clones of single crystal diamond with 1-inch size, Diam. Relat. Mater. 24 (2012) 29-33.

[11] H. Yamada, A. Chayahara, Y. Mokuno, Y. Kato, S. Shikata, A 2-in. mosaic wafer made of a single-crystal diamond. Appl. Phys. Lett. 104 (2014) 102110.

[12]T. Bauer, S. Gsell, M. Schreck, J. Goldfug, J. Lettieri, D.G. Schlom, B. Stritzker, Diam. Relat. Mater. 14 (2005) 314-317.

[13]M. Schreck, S. Gsell, R. Brescia, M. Fischer, Ion bombardment induced buried lateral growth: the key mechanism for the synthesis of single crystal diamond wafers, Sci. Rep. 7 (2017) 44462. 
[14]Y. Mokuno, Y. Kato, N. Tsubouchi, A. Chayahara, H. Yamada, S. Shikata, Nitrogen doped low-dislocation density free-standing single crystal diamond plate fabricatedby lift-off process, Appl. Phys. Lett. 104 (2014) 252109.

[15] Q. Liang, C.Y. Chin, J. Lai, C. Yan, Y. Meng, H. Mao, R.J. Hemley,Enhanced growth of high quality single crystal diamond by microwave plasma assisted chemical vapor deposition at high gas pressures, Appl. Phys. Lett. 94(2009) 024103.

[16]J. L. O’Brien, Optical quantum computing, Science, 318 (2007) 1567-1570.

[17]A. Tallaire, C. Rond, F. Be' ne' dic, O. Brinza, J. Achard, F. Silva, A Gicquel,Effect of argon addition on the growth of thick single crystal diamond by high-power plasma CVD.Phys. Status Solidi A, 208 (2011) 2028-2032.

[18]Y. Sua, H.D. Lia,n, S.H. Cheng,Effect of $\mathrm{N}_{2} \mathrm{O}$ on high-rate homoepitaxial growth of CVD single crystal diamonds.J. Cryst. Growth, 351 (2012) 51-55.

[19] Y. Liou, A. Inspektor, R. Weimer, D. Knight, R. Messier,The effect of oxygen in diamond deposition by microwave plasma enhanced chemical vapor deposition,J. Mater. Res. 5 (1990) 2305-2312.

[20] Q. Liang, C. Yan, Y. Meng, J. Lai, S. Krasnicki, H. Mao, R.J. Hemley, Recent advances in high- growth rate single-crystal CVD diamond. Diam. Relat. Mater.18 (2009) 698-703.

[21] N. Tsubouchi, S. Shikata, Evaluation method for grown-in dislocations in CVD single crystal diamond using plasma surface treatment, Jpn. J. Appl. Phys. 53 (2014) 068010.

[22]M. Naamoun, A. Tallaire, F. Silva, J. Achard, P. Doppelt, A. Gicquel, Etch-pit formation mechanism induced on HPHT and CVD diamond single crystals by $\mathrm{H} 2 / \mathrm{O} 2$ plasma etching treatment. Phys. Status Solidi A, 209 (2012) 1715-1720.

[23]J. Achard, F. Silva, O. Brinza, X. Bonnin, V. Mille, R. Issaoui, M. Kasu, A. Gicquel, Identification of etch-pit crystallographic faces induced on diamond surface by $\mathrm{H} 2 / \mathrm{O} 2$ etching plasma treatment, Phys. Status Solidi A, 206 (2009) 1949-1954.

[24] S.A. Linnik, A.V. Gaydaychuk, Application of optical emission spectroscopy for the determination of optical CVD diamond growth parameters in abnormal glow discharge plasma, Vaccum, 103 (2014) 28-32.

[25] D. Das, Raj N. Singh, I. T. Barney, A. G. Jackson, S. M. Mukhopadhyay, Effect of oxygen on growth and properties of diamond thin film deposited at low surface temperature, J. Vac. Sci. Technol. B,26 (2008) 1487-1495.

[26] G.C.Chen, B. Li, H. Li, H. Lan, F.W. Dai, Q.J. Xue, X.Q. Han, L.F. Hei, J.H. Song, C.M. Li, W.Z. Tang, F.X. Lu, Growth of diamond by DC Arcjet Plasma CVD: From nanosized poly-crystal films to millimeter-sized single crystal grain, Diam. Relat. Mater. 19 (2010) 1078-1084.

[27] A. Tallaire, J. Achard, F. Silva, R.S. Sussmann, A. Gicquel, E. Rzepka, Oxygen plasma pre-treatments for high quality homoepitaxial CVD diamond deposition. Phys. Status Solidi A, 201 (2004) 2419-2424.

[28] L. Hei, J. Liu, F. Lu, C. Li, J. Song, G. Chen. Effect of growth parameters on single crystal diamond deposition by DC Arc Plasma Jet CVD. Adv. Mat. Res.490-495 (2012) 30943099.

[29] P.K. Tyagi, A.M. N. Unni, P. Rai, M.K. Singh, U. Palnitkar, D.S. Misra, F.Le Normand, M. Roy, S.K. Kulshreshtha,Step growth in single crystal diamond grown by microwave plasma chemical vapor deposition, Diam. Relat. Mater. 15 (2006) 304-308. 


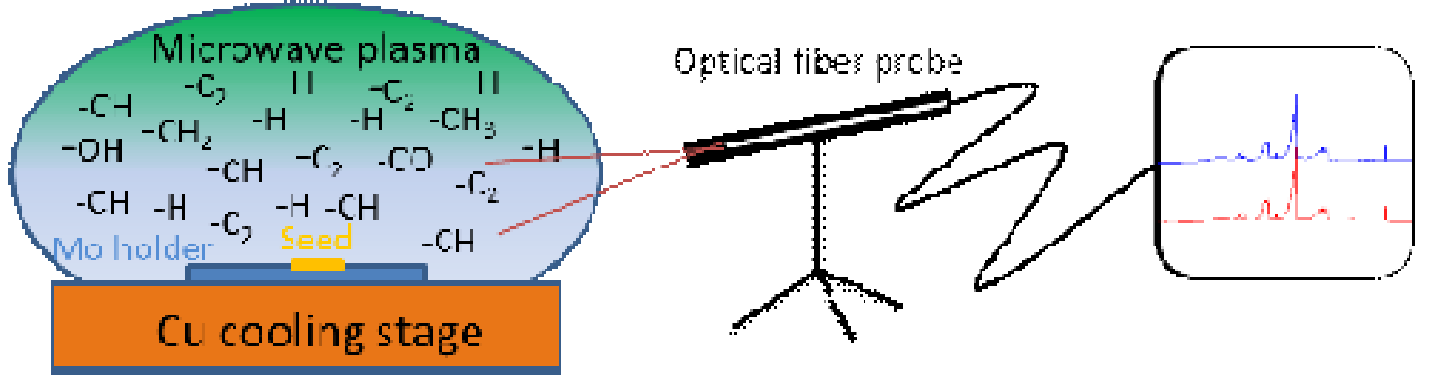

Fig. 1 Schematic diagram of the optical emission spectroscopy to test the active radicals in diamond growth environment with $\mathrm{O}_{2}$ addition. 

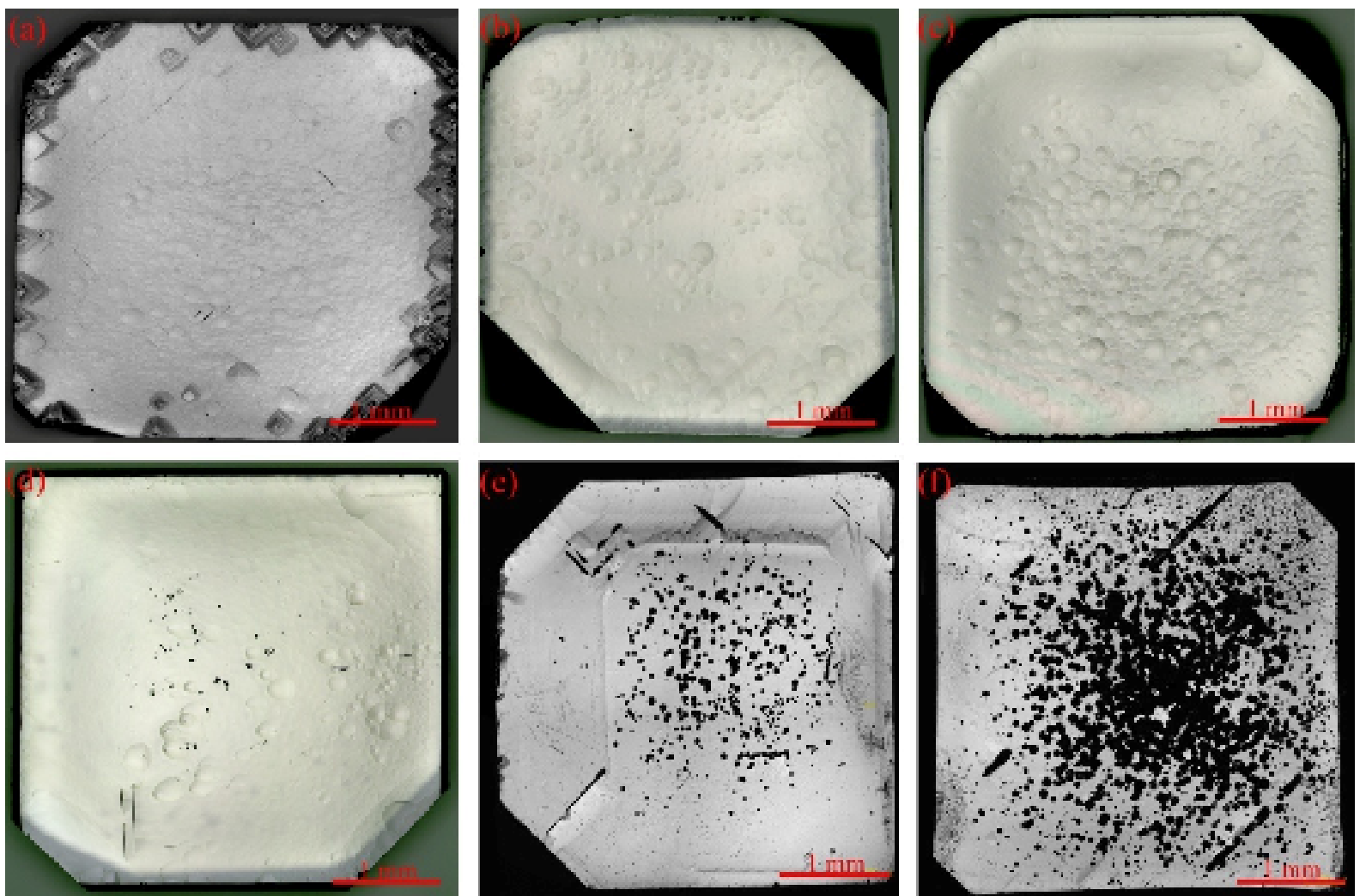

Fig. 2 The photos of the epitaxial single crystal diamond films grown with different $\mathrm{O}_{2}$ concentration (A1) $0 \%,(\mathrm{~A} 2) 0.5 \%,(\mathrm{~A} 3) 1 \%,(\mathrm{~A} 4) 1.5 \%,(\mathrm{~A} 5) 2 \%$, and (A6) $2.5 \%$ 
(a)

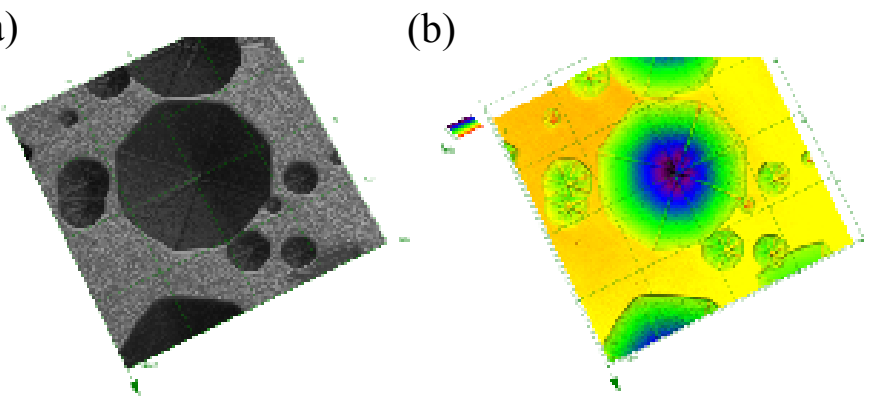

(c)

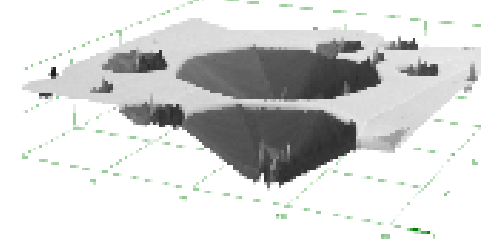

Fig.3 The laser scanning confocal micrographs of the etching pits in Fig.1 (A6).

(a) surface morphology, (b) image of contour and (c) 3D morphology 
(a)

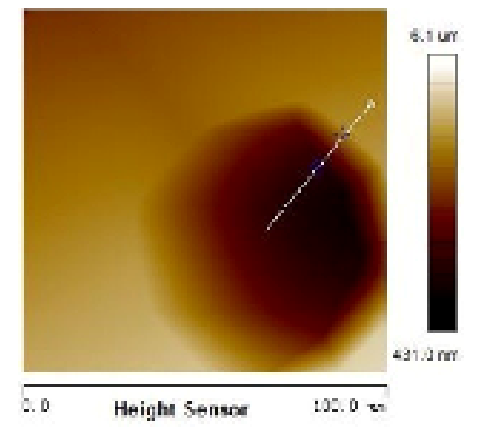

(b)

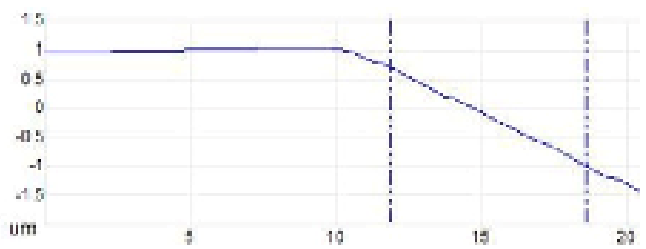

Fig.4 The surface morphology of the etching pits (a) tested by AFM and the surface profile of one crystallographic plane (b) 

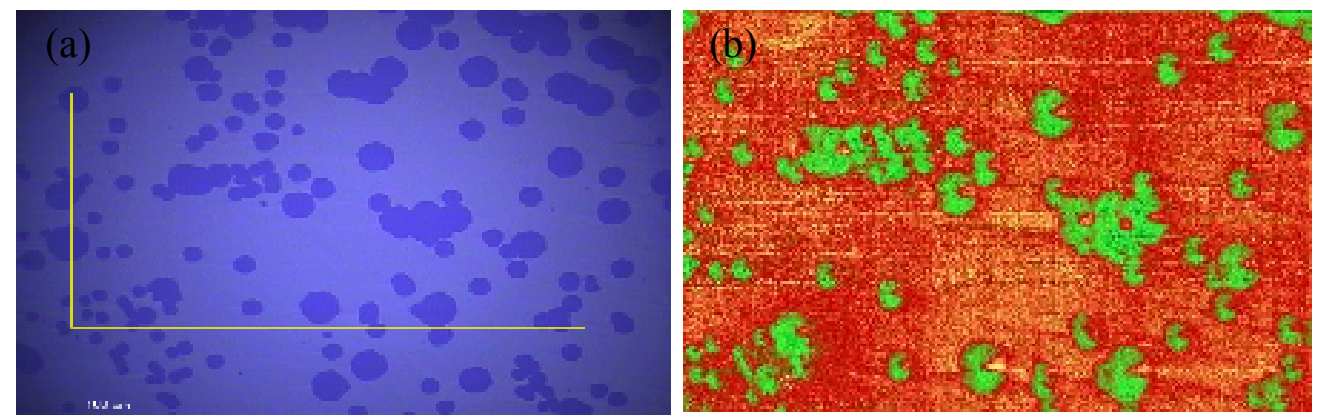

Fig.5 The surface microstructure of A6 (a) and corresponding Raman mapping in the yellow box (b) based on the intensity of characteristic peak of diamond 
(a)

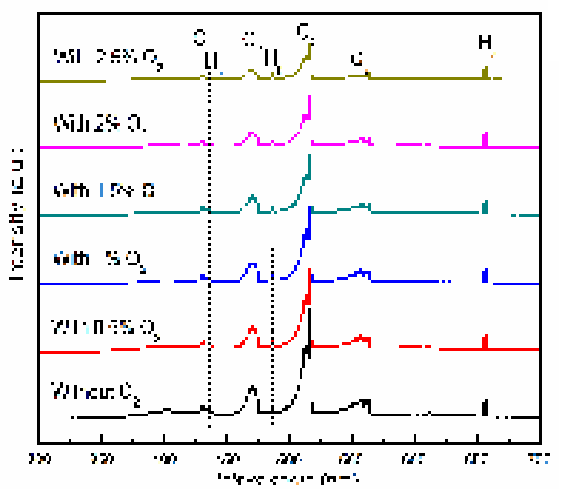

(b)

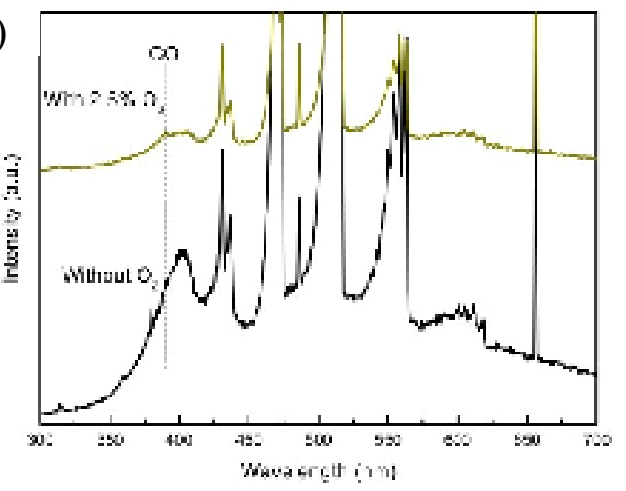

Fig. 6 Optical emission spectra of the $\mathrm{O}$ contained plasma during diamond deposition varying $\mathrm{O}_{2}$ addition from $0 \%$ to $2.5 \%$ in the $\mathrm{H}_{2} / \mathrm{CH}_{4}$ plasma (a) and comparison of optical emission spectra of the plasmas with and without $\mathrm{O}_{2}$ addition (b). 


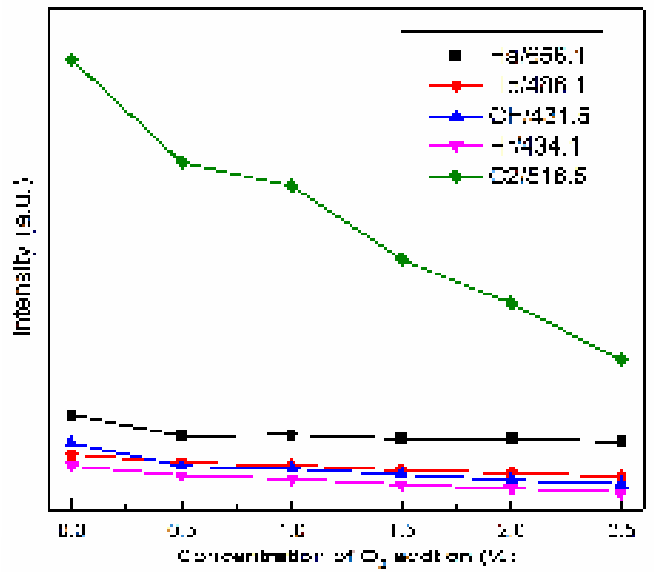

Fig.7 Effect of oxygen concentration on the different radical intensity in the plasma obtained from the optical emission spectra in Fig.5 
(a)

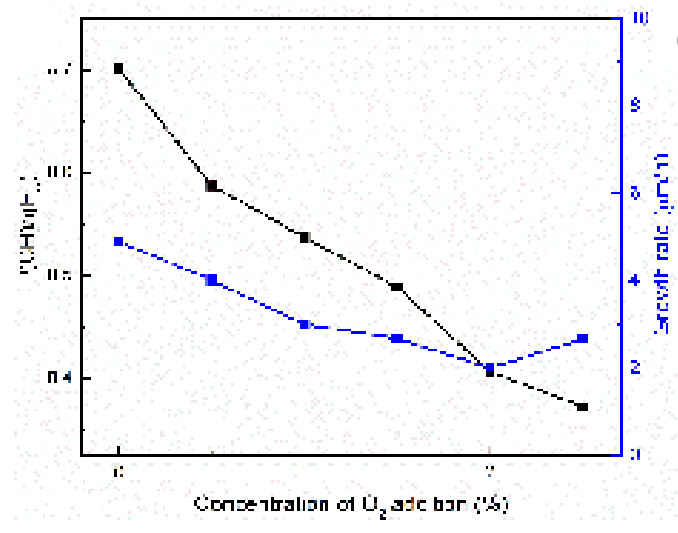

(b)

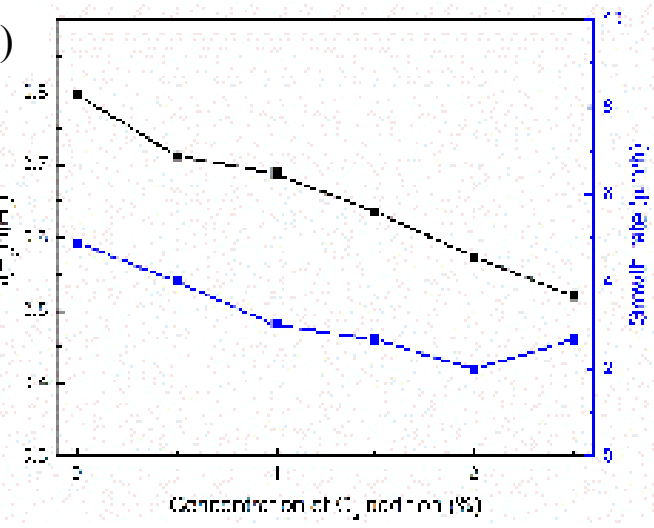

Fig. 8 Dependence of the relative intensity of $\mathrm{CH}$ to $\mathrm{H}_{\alpha}$ emissions, $I(\mathrm{CH}) / I\left(\mathrm{H}_{\alpha}\right)(\mathrm{a})$, and $\mathrm{H}_{\gamma}$ to $\mathrm{H}_{\beta}$ emission intensity $\left(I\left(\mathrm{H}_{\gamma}\right) / I\left(\mathrm{H}_{\beta}\right)(\mathrm{b})\right.$ and growth rate on the $\mathrm{O}_{2}$ addition in the $\mathrm{H}_{2} / \mathrm{CH}_{4}$ plasma. 


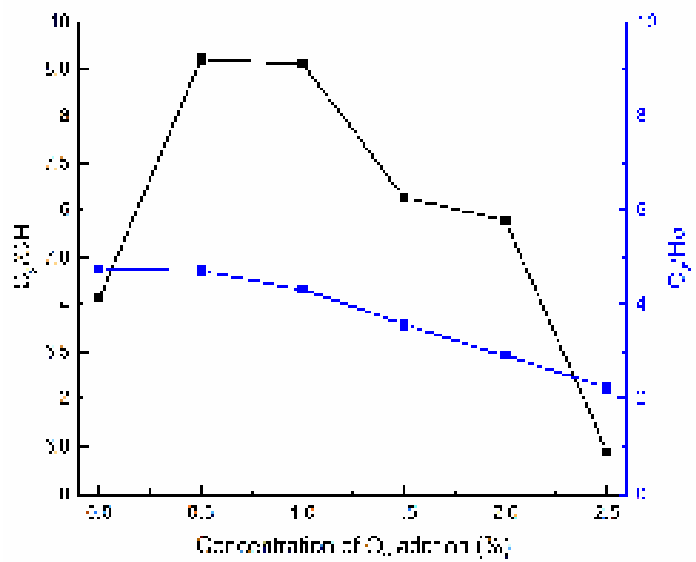

Fig.9 Dependence of the relative intens ity of $\mathrm{C}_{2}$ to $\mathrm{CH}$ emissions, and the relative intensity of $\mathrm{C}_{2}$ to $\mathrm{H}_{\alpha}$ emissions, 


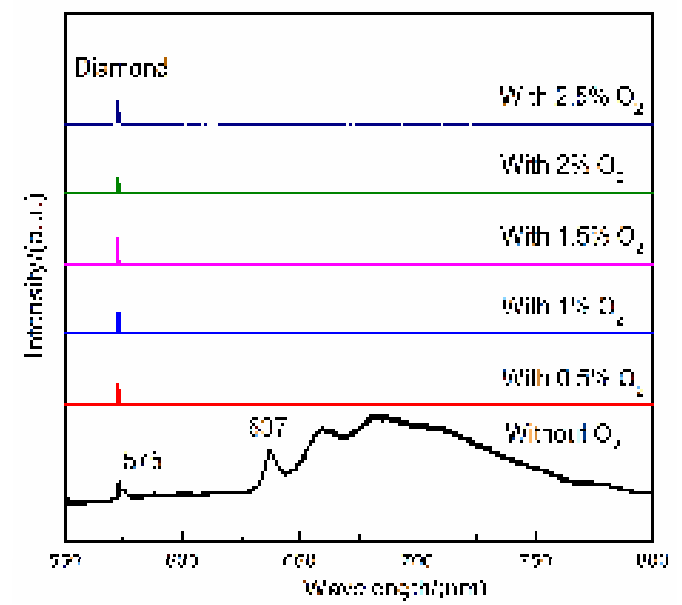

Fig.10 Photoluminescence (PL) spectra taken from the epitaxial diamond layers grown at different concentrations of $\mathrm{O}_{2}$ with laser excitation of $532 \mathrm{~nm}$ at $77 \mathrm{~K}$. 
(a)

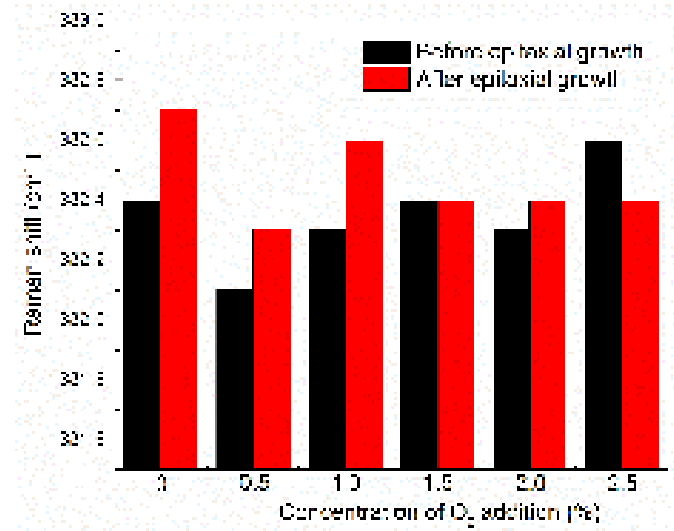

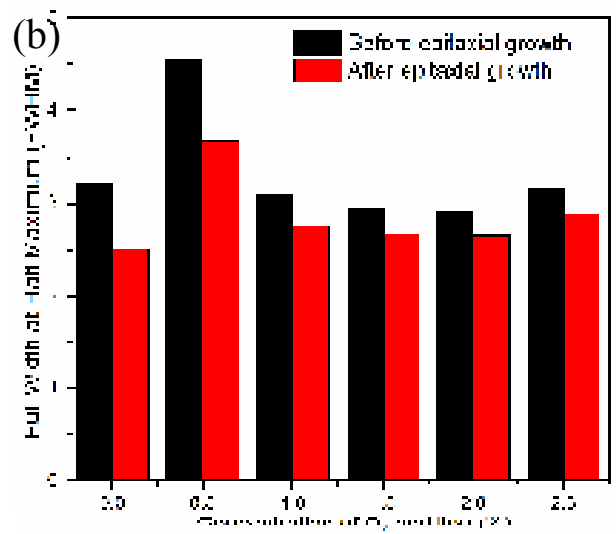

Fig.11 The comparison of the characteristic peak position (a) and FWHM (b)of the diamond seeds and epitaxial growth layers with different concentrations of $\mathrm{O}_{2}$ addition. 


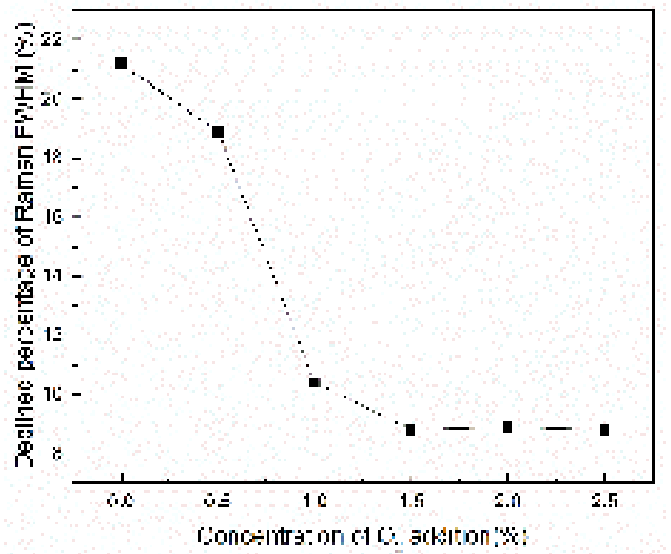

Fig. 12 The declined percentage of the Raman FWHM versus the concentration of $\mathrm{O}_{2}$ addition 
Table 1 The growth parameters of single crystal diamonds with $\mathrm{O}_{2}$ addition at different concentrations

Power/kW Cha mber Pressure/ $\mathrm{kPa} \mathrm{CH}$ flow/sccm $\mathrm{O}_{2}$ concentration $\left(\mathrm{O}_{2} / \mathrm{H}_{2}\right) / \%$ Time/h

\begin{tabular}{|c|c|c|c|c|}
\hline 2.6 & $22-24$ & 15 & $\begin{array}{l}0 \\
0.5 \\
1 \\
1.5 \\
2 \\
2.5\end{array}$ & 15 \\
\hline
\end{tabular}

